\title{
ÓRganos CONSTITUCIONALES AUtÓNOMOS Y HEGEMONÍA DE PARTIDO
}

\author{
KARIME PÉREZ GUZMÁN ${ }^{1}$
}

RESUMEN: Este trabajo es un sencillo análisis del surgimiento de los órganos constitucionales autónomos en relación con la hegemonía de partidos. Esta investigación intenta determinar si existe un vínculo entre el incremento de órganos constitucionales autónomos y la desaparición de un partido hegemónico en México. Es decir, si la alternancia partidista en el cargo de Presidente de la República ha tenido alguna influencia en el aumento de facultades autónomas en el ejercicio del poder.

PALABRAS CLAVE: Órganos constitucionales autónomos, poder, hegemonía, partidos políticos, alternancia.

ABSTRACT: This work is a simple analysis of the emergence of the autonomous constitutional organisms in relation to the hegemony of parties. This investigation tries to determine if there is any relationship between the increase of autonomous constitutional organisms and the disappearance of a hegemonic politic party in Mexico. That is to say, if the partisan alternation in the position of President of the Republic has had some influence on the increase of autonomous powers in the exercise of power.

KEYWORDS: Autonomous constitutional organisms, power, hegemony, political parties, alternation.

SUMARIO: I. Introducción; II. Hegemonía de partido y presidencialismo; III. Surgimiento de los órganos constitucionales autónomos en México; IV. Análisis de la relación entre la alternancia de partido del que emerge el Presidente de la República y el incremento de los órganos constitucionales autónomos; V. Conclusiones; VI. Fuentes.

1 Secretaria de Tribunal del Poder Judicial de la Federación. 


\section{InTRODUCCIÓN}

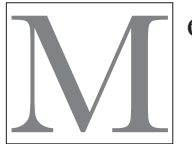

éxico es un país pluripartidista. A la fecha en que se escribe el presente trabajo, en la página electrónica oficial del Instituto Nacional Electoral aparece un directorio de nueve partidos políticos con registro a nivel federal ${ }^{2}$ sin embargo, eventualmente la lista seguirá creciendo pues continuamente hay nuevas organizaciones políticas en formación.

No obstante, la historia posrevolucionaria mexicana se encuentra marcada por la prevalencia de un partido político del que por más de 70 años surgió el Presidente de la República y la mayoría de los integrantes del Congreso de la Unión.

Aunque con distintos nombres, el actual Partido Revolucionario Institucional guió el desarrollo de las instituciones y abonó a la construcción de un presidencialismo muy sólido en el que el titular del Ejecutivo era más que Jefe de Estado y de Gobierno, pues contaba con facultades constitucionales y meta-constitucionales que lo hacían superponerse a los poderes Legislativo y al Judicial, en lo que al ejercicio del poder se refiere.

Esta etapa hegemónica comenzó a tambalearse en 1988, en la contienda electoral entre Carlos Salinas de Gortari (postulado por el PRI) y Guauhtémoc Cárdenas Solórzano (candidato del PRD), pues la popularidad de este último y la pequeña diferencia de votos que finalmente le dio el triunfo al primero, generó mucha especulación de un posible fraude electoral.

Precisamente en el sexenio de Carlos Salinas surgió el primero de los organismos constitucionales autónomos: el Banco de México, en 1993.

A partir de entonces, han nacido en la Constitución Política de los Estados Unidos Mexicanos, un número creciente de órganos au-

2 Instituto Nacional Electoral, Directorio y documentos básicos, <http://port alanterior .ine. $\mathrm{mx} /$ archivos 3/ portal /histórico /contenido /Directorio_y_do cumentos _ ba sicos/>, consultado el 4 de mayo de 2018 . 
tónomos. Hoy suman 10, de los cuales 6 obtuvieron su autonomía constitucional en un solo sexenio (de 2012 a 2018).

El objeto de este estudio académico es la disgregación del poder público que ejercía el titular del Ejecutivo y su trasferencia a los órganos constitucionales autónomos y su posible vínculo con la extinción de la hegemonía de partidos.

Las incógnitas que se tratarán de abordar y despejar para sustentar este trabajo de investigación y análisis son las siguientes:

a) ¿Qué relación existe entre la hegemonía de partido y el presidencialismo mexicano?;

b) ¿En qué contexto se dio la alternancia en el cargo de Presidente de la República?

c) ¿Cómo surgieron los órganos constitucionales autónomos en México?

Con base en las respuestas a estas premisas se sustenta la hipótesis siguiente:

Los órganos constitucionales autónomos son una forma de disgregación del poder político cuyo surgimiento e incremento se relaciona con la terminación de la hegemonía partidista.

\section{Hegemonía de partido y PREsidencialismo}

\section{PARTIDO HEgEMÓNICO}

De acuerdo con el diccionario de la Real Academia Española, ${ }^{3}$ la palabra hegemonía significa supremacía de cualquier tipo.

Para efectos del presente estudio, el término hegemonía debe entenderse como preeminencia o preponderancia de un grupo sobre otros.

3 Diccionario de la Real Academia Española. Versión virtual, <http://dle. rae.es/?id=K5aAUck $>$, consultado el 2 de mayo de 2018. Consultado el 7 de mayo de 2018 . 
Así, cuando se hace referencia al término "partido hegemónico", se alude a aquel que, sin ser el único en un sistema político, se superpone a los demás existentes.

Este concepto se construyó después de la revolución rusa de 1905, para describir la relación del Partido Bolchevique con el proletariado. $^{4}$

Por su parte, en su clasificación de sistemas de partidos, Sartori se refirió al "sistema de partido hegemónico" como aquel en el que existe uno dominante, es decir, uno más fuerte en el gobierno en la medida en que se ve apoyado por la mayoría de votos. En este tipo de organización política puede haber más de un partido pero sin que esa circunstancia represente una oposición real. ${ }^{5}$

En México, cuando se habla de "régimen de partido hegemónico" se entiende el sistema de partidos controlado por el PRI. Se trata de un modelo que no admite competencia por el poder, aunque sí consciente la existencia de otros partidos, no obstante que estos se encuentren impedidos para competir frontalmente y en igualdad de circunstancias con el hegemónico debido a la capacidad de aquel para controlar el acceso a los cargos públicos, provocando que quienes aspiran a un puesto de elección popular se vean en la necesidad de integrarse a ese partido dominante, con lo que implícitamente lo refuerzan y le dan continuidad a su supremacía. ${ }^{6}$

En México, los orígenes del partido hegemónico se encuentran vinculados estrechamente con la historia postrevolucionaria. En esa época el país se encontraba dividido en distintos poderes regionales

4 Cfr. Rodríguez Montaño, Luis Carlos y Pineda Pablos, Nicolás, "La declinación de la hegemonía del PRI en los gobiernos estatales de México, 1989-2014". Revista Scielo, vol. 29, núm. 69, 2017, pp.127-152, <http://www.scielo.org.mx/ pdf/regsoc/v29n69/1870-3925-regsoc-29-69-00127.pdf>, consultada el 11 de mayo de 2018.

5 Véase Sartori, Giovanni, Partidos y sistemas de Partidos, 2 ${ }^{\mathrm{a}}$ Ed., trad. de Fernando Santos Fontela, Madrid, Alianza Editorial, 2005, pp.281-292.

6 Cfr. Rodríguez Montaño, Luis Carlos y Pineda Pablos, Nicolás, op. cit. 
tales como caciques militares, caudillos revolucionarios y grupos de choque, lo que generaba luchas entre los caciques y los partidos, y entre aquellos y los grupos políticos. Aunque existían diversas organizaciones obreras y campesinas con diversos pesos políticos, estas estaban muy dispersas; y también había grupos sindicales que luchaban por la supremacía. ${ }^{7}$

En este contexto, aparecían y desaparecían una gran cantidad de partidos estatales y municipales circunstancialmente a las épocas electorales, pues solo eran usados como instrumentos por los caciques locales. Así, no obstante esta abundancia de partidos, no existía un "gran partido nacional" (como lo llama Tiziana Bertaccini), ni un sistema de partidos que diera estabilidad a la vida política. ${ }^{8}$

Según lo explica Manuel Zúñiga Aguilar, con el asesinato en 1928 del General Álvaro Obregón, único actor político que tenía la capacidad de aglomerar a los distintos grupos surgidos de la revolución, se hizo necesaria la creación del Partido Nacional Revolucionario (PNR) de manera que con Plutarco Elías Calles encabezando el comité organizador, se pronunciaron los primeros manifiestos ante la urgencia de contar con un candidato a Presidente de la República que fuera respaldado por las principales fuerzas políticas del país. ${ }^{9}$

A partir de 1938, este partido cambió de nombre a Partido de la Revolución Mexicana (PRM), denominación que mantuvo hasta

7 Véase Bertaccini, Tiziana, "Volver a las orígenes del Partido Revolucionario Institucional: una mirada comparativa con el Partido Nacional Fascista", Revista Electrónica Iberoamericana, Centro de Estudios Iberoamericanos, vol. 10, num. 2, 2016, p. 5. <https://www.urjc.es/images/ceib/revista_electronica/vol_10_2016_2/ REIB_10_02_Art5.pdf>, consultada el 7 de mayo de 2018.

8 Idem.

9 Véase Zúñiga Aguilar, Manuel, "Partido Nacional Revolucionario (PNR). Método y práctica en la selección de candidatos a puestos de elección popular (1929-1938)", Estudios Políticos, México, novena época, núm. 24, septiembre-diciembre, 2011 , pp. 33-53 <http://www.journals.unam.mx/index.php/rep/article /view/27399/25426>, consultado el 4 de mayo de 2018. 
1946, año en que se le asignó la de Partido Revolucionario Institucional que mantiene hasta la actualidad. ${ }^{10}$

Ahora bien, el bien ganado calificativo de partido hegemónico que el PRI mantuvo hasta las elecciones del 2000 (en que por primera vez desde su nacimiento, la Presidencia de la República fue obtenida por un candidato de la oposición, el Partido Acción Nacional -PAN-), se debe a que de este instituto político surgieron ininterrumpidamente (hasta ese año) los titulares del Ejecutivo mexicano, lo que generó una dinámica en la cual el Presidente de la República manejaba a su vez al partido, y este servía al primero en aras de preservar su supremacía.

Efectivamente, aun cuando formalmente el partido oficial nunca constituyó un órgano estatal, ni constitucional o legalmente se estableció un vínculo jurídico entre este y el Estado; lo cierto es que el Presidente de la República era considerado el jefe supremo del partido, pues si bien existían un presidente y un secretario electos de acuerdo con los estatutos y que además no ocupaban a la vez puestos en el gobierno; la verdad de las cosas es que el cargo de presidente del partido (que era electivo), se renovaba cada seis años con el Ejecutivo Federal y quedaba a cargo de algún militante cercano al titular de aquel; de manera que en los hechos el partido seguía los lineamientos del presidente en turno, aunque oficialmente emitiera de manera autónoma sus propios documentos internos. Era pues, una forma de aparentar que las decisiones de partido se asumían por sus propios órganos de gobierno (asambleas nacionales, consejo nacional, comité ejecutivo nacional, etcétera), cuando en realidad constituía una estructura de apoyo al gobierno para fortalecer al aparato estatal. ${ }^{11}$

10 Véase Zúñiga Aguilar, Manuel, "89 datos del PRI en 89 años de historia", Expansión en alianza con CNN, México, 4 de marzo de 2018, <https:/ / expansion.mx/ economia/2016/03/03/87-datos-del-pri-en-87-anos-de-historia>, consultada el 8 de mayo de 2018.

11 Véase Bertaccini, Tiziana, op. cit. p. 12. 
Lo anterior, se apuntalaba con una mayoría dominante en el Congreso de la Unión, cuyos diputados y senadores, electos de manera directa, emanaban de las filas del PRI; y consecuentemente, la Suprema Corte de Justicia de la Nación también resultaba afín a los intereses priístas. Esto último se afirma con base en que, desde 1917 la manera de designación de los Ministros ha estado a cargo del legislativo, primero; y posteriormente del Senado y del Ejecutivo.

Así es, en el texto constitucional finalmente aprobado por el Constituyente de Querétaro en 1917, se asentó que el máximo tribunal estaría integrado por once ministros inamovibles designados por las Cámaras de Diputados y Senadores reunidas en funciones de Colegio Electoral. Esta inamovilidad no era inmediata, sino que los ministros durarían dos años, después se renovarían (por las propias cámaras) por otros cuatro y a partir de ahí serían inamovibles. ${ }^{12}$

Actualmente, de acuerdo con el artículo 94 constitucional (a partir de la reforma de 1994), la Suprema Corte de Justicia de la Nación, se integra por once Ministros, que durarán en su encargo quince años, y sólo podrán ser removidos por responsabilidad en el desempeño de sus funciones. ${ }^{13}$

Por cuanto al procedimiento de designación de los ministros, el artículo 96 constitucional señala que el Presidente de la República someterá una terna a consideración del Senado, el cual, previa comparecencia de las personas propuestas, designará al Ministro que deba cubrir la vacante. La designación se hará por el voto de las dos terceras partes de los miembros del Senado presentes, dentro del improrrogable plazo de treinta días. Si el Senado no resolviere dentro de dicho plazo, ocupará el cargo de Ministro la persona que, dentro de dicha terna, designe el Presidente de la República. En caso de que la Cámara de Senadores rechace la totalidad de la

12 Cfr. Cabrera Acevedo, Lucio, El Constituyente de 1917 y el Poder Fudicial de la Federación, una visión del siglo $X X$, México, Suprema Corte de Justicia de la Nación, 2002, pp. 60 a 100.

13 Constitución Política de los Estados Unidos Mexicanos. 
terna propuesta, el Presidente de la República someterá una nueva, en los términos del párrafo anterior. Si esta segunda terna fuera rechazada, ocupará el cargo la persona que dentro de dicha terna, designe el Presidente de la República. ${ }^{14}$

En un régimen presidencial como el mexicano, esta práctica hegemónica decantó en lo que Carpizo denominó "presidencialismo puro", así considerado por su ausencia de rasgos parlamentarios. ${ }^{15}$

\section{Presidencialismo}

Para el Doctor Dardo Pérez Guilhou, los antecedentes de un presidencialismo fuerte en América Latina se remontan a la historia colonial que lo precedió. Explica que la concentración de funciones en el titular del Ejecutivo tiene características heredadas de la época en que el gobierno colonial en América era ejercido por virreyes, gobernadores y tenientes gobernadores que aunado a sus títulos ostentaban los de generales, capitanes y justicias mayores; lo que les permitía llevar a cabo funciones de gobierno, guerra y justicia. ${ }^{16}$

Como es bien sabido, un régimen presidencial se caracteriza básicamente porque de entre la distribución de las funciones del Estado, recaen en el titular del Ejecutivo (Presidente) las relativas a la administración y jefatura de Estado; pero además porque este

14 Constitución Política de los Estados Unidos Mexicanos.

15 Véase Carpizo, Jorge, "Presidencialismo Puro", en Flores Mendoza, Imer Benjamín (ed. y coord.), Doctrina Constitucional Mexicana colección INEHRM, México, Senado de la República LXIII Legislatura, Secretaría de Cultura, Instituto Nacional de Estudios Históricos de las Revoluciones de México, Instituto de Investigaciones Jurídicas-UNAM, 2017, pp. 369 a 381.

16 Véase Pérez Guilhou, Dardo, "Presidencialismo, caudillismo y populismo", Comunicación en sesión privada de la Academia Nacional de Ciencias Morales y Políticas, el 13 de abril de 2005, <https://www.yumpu.com/es/document/ view/29447475/presidencialismo-caudillismo-y-populismo-academia-nacional -de->, consultado el 4 de mayo de 2018 
tiene facultades que implican "formas de control" principalmente dirigidas al Legislativo. ${ }^{17}$

Jorge Carpizo destacó que la característica principal del presidencialismo mexicano era la predominancia de la figura del Presidente respecto de los titulares de los otros poderes. Esta superioridad la atribuyó al debilitamiento del Poder Legislativo y a la pasividad de un Poder Judicial coincidente con los intereses del Ejecutivo (según se adelantó en párrafos precedentes); pero además, a las facultades meta constitucionales derivadas, entre otras cosas, de la hegemonía del partido político presidencial. ${ }^{18}$

Así es, se trata de un sistema político en el que un solo partido tiene a la vez la posición de Presidente de la República y la mayoría en el Congreso; por lo que, consecuentemente, es la misma ideología y los mismos intereses los que prevalecen en la designación de los titulares del Poder Judicial.

Además, el Doctor Carpizo enfatizó que esa misma hegemonía originó una dinámica en la que el Presidente era a la vez jefe de partido; y como tal, tenía a su cargo la potestad (meta constitucional) de decidir quién sería su sucesor, así como designar a quienes ocuparían los cargos de gobernadores y presidentes municipales. ${ }^{19}$

En opinión de Daniel Márquez, con esta idea Carpizo logró integrar los aspectos objetivo y subjetivo del fenómeno del presidencialismo, ya que por una parte analizó las normas jurídicas y por otra los aspectos sociológicos, políticos y culturales que hacían del Presidente de la República el referente político del país. Esto se des-

17 Véase Presidencialismo y Parlamentarismo en la jurisprudencia constitucional. IX Conferencia Iberoamericana de Justicia Constitucional. IX Conferencia Iberoamericana de Justicia Constitucional. Cádiz, 17, 18 y 19 de mayo de 2012, <https://www.tribunalconstitucional. es/es/publicaciones/Publicaciones/ CIJC -IX.pdf>, consultado el 4 de mayo de 2018.

18 Véase Carpizo, Jorge, El Presidencialismo Mexicano, 2a edición, México, Editorial Siglo XXI, 2011.

19 Véase Carpizo, Jorge, "Presidencialismo...", op. cit. , pp. 369 a 381. 
taca en la división que hizo Carpizo de las facultades presidenciales en Constitucionales y meta constitucionales, con lo que, a juicio de Márquez, incluyó categorías sociales en el análisis jurídico, superando la visión reduccionista del positivismo y mostró la tensión entre realidad y norma. ${ }^{20}$

Sin embargo, para diversos analistas, el sistema político mexicano actual ha transitado de ese Ejecutivo absolutamente dominante sostenido a por un partido totalmente mayoritario, a un pluripartidismo en el que el Presidente de la República necesita construir su solidez en la gestión política cotidiana, con un congreso integrado por diversas fuerzas políticas y un Poder Judicial que ha recobrado casi totalmente el espacio que le corresponde en el diseño político original teórico de división de equilibrio de funciones. ${ }^{21}$

Con independencia de si se comparte la opinión anterior, lo cierto es que actualmente el poder político del presidente de la República ya no es absoluto. Pero, ¿dónde comenzó esta disminución en sus facultades constitucionales y sobre todo, meta constitucionales? Una posible respuesta a esta pregunta, es que inició con la alternancia.

20 Véase Márquez, Daniel, "Fenomenología, presidencialismo mexicano y facultades meta constitucionales", en Carbonell, Miguel, Fix-Fierro, Héctor, González Pérez, Luis Raúl y Valadés, Diego (coords), Estado Constitucional, derechos humanos, justicia y vida universitaria. Estudios en homenaje a forge Carpizo, México, Universidad Nacional Autónoma de México Instituto de Investigaciones Jurídicas, 2015 , pp. 289 a 315.

21 Véase Arroyo Ramírez, Miguel, "Notas al Presidencialismo Mexicano”, en Carbonell, Miguel, Fix-Fierro, Héctor, González Pérez, Luis Raúl y Valadés, Diego (coords), Estado Constitucional, derechos humanos, justicia y vida universitaria. Estudios en homenaje a Forge Carpizo, México, Universidad Nacional Autónoma de México Instituto de Investigaciones Jurídicas, 2015, pp. 105 a 115. 
La transición de nuestro país de un régimen presidencialista puro y de partido hegemónico, a un sistema partidista no fue inmediata. Según Juan Pablo Navarrete Vela, este proceso implicó un largo periodo de cambios jurídicos y sociales. ${ }^{22}$

A juicio de este autor son dos los factores principales que poco a poco fueron moldeando la derrota del Partido Revolucionario Institucional en el año 2000; en primer lugar la presión de la oposición por constituirse como una real fuerza política oponible al partido dominante y en segundo término las reformas constitucionales y legales en materia electoral que le allanaron el camino.

Esto no ocurrió de un día a otro, sino que se trató de un proceso largo que posiblemente tiene su origen en 1968, en que se inició un proceso de apertura por parte del sistema autoritario. ${ }^{23}$ Esto sin duda, a raíz de la situación política que imperaba en el país y a la observación internacional de que fue objeto el gobierno mexicano ante los movimientos estudiantiles y sociales de ese momento y la actitud represiva con la que el sistema los sofocó. Recordemos que ese mismo año se celebraron en México los Juegos Olímpicos y los periodistas internacionales transmitieron a muchas partes del mundo imágenes reveladoras de la situación imperante en nuestro país. ${ }^{24}$

Esta constante tensión entre el gobierno y la sociedad trajo como resultado un intento de apertura controlada que desembocó en la

22 Véase Navarrete Vela, Juan Pablo, "Sistema político mexicano: Desarrollo y reacomodo del poder". Ibero Fórum, Universidad Iberoamericana, vol III, núm. 6, julio-diciembre, 2008, pp 131-148, <http://www.ibero.mx/iberoforum/6/ pdf/juann.pdf>, consultado el 14 de mayo de 2018

23 Idem.

24 Del Castillo Troncoso, Alberto, "El movimiento estudiantil de 1968 narrado en imágenes" Revista Scielo, año 23, núm. 68, septiembre-diciembre de 2008, pp. 63-114, <http://www. scielo.org. mx/pdf/soc/v23n68/v23n68a4 .pdf>, consultada el 8 de mayo de 2018. 
reforma electoral de 1973, durante el sexenio de Luis Echeverría Álvarez.

Esta reforma había comenzado en $1971^{25}$ cuando el porcentaje de votación requerido para tener derecho a una diputación de partido disminuyó, de 2.5 a $1.5 \%$, y el número máximo de diputados de partido por organización minoritaria se elevó de 20 a 25. En 1973, mediante la nueva ley electoral, se concedió tiempo en radio y televisión a los partidos durante las campañas electorales y se redujo el número de afiliados necesarios para su registro legal de 75,000 a $65,000 .{ }^{26}$

Por su parte, la reforma de 1977 tenía por objeto abrir espacios a las minorías, luego de un proceso electoral en el que el candidato del PRI, José López Portillo, había participado solo, es decir, sin otro candidato opositor, ya que el PAN había determinado no contender en ese proceso; de modo que el priísta obtuvo la presidencia con el $100 \%$ de los votos válidos. ${ }^{27}$

Como resultado de esta importante reforma, se logró la incorporación del mecanismo de representación proporcional en la Cámara de Diputados para la designación del 25\% de sus integrantes, es decir, 100 de los 400 diputados que a partir de entonces integraban a dicha Cámara, serían electos mediante este proceso. Con esto se inaugura el sistema de elección mixto para la conformación de ese órgano legislativo.

25 Durante el sexenio de López Mateos ya se habían instaurado los denominados "diputados de partido", ya que se exigía un porcentaje de $25 \%$ del total de los votos válidos en las elecciones para tener derecho a esta diputación y cada partido podía tener un máximo de 20.

26 Fernández, Nuria, "La reforma política: Orígenes y limitaciones", Cuadernos Políticos, núm. 16, México, editorial Era, abril-junio de 1978, pp. 16-30, <http://www. cuadernos politicos .unam. mx/ cuadernos/contenido/CP.16/ CP16.4. Nuria Fernandez.pdf>, consultado el 12 de mayo de 2018.

27 Aguilar Camín, Héctor, "Nocturno de la democracia mexicana", Nexos, 1 de mayo de 2016, <https://www.nexos.com.mx/?p=28283>, consultado el 14 de mayo de 2018 . 
También se dio la posibilidad de que más agrupaciones políticas obtuvieran su registro como partidos políticos a través del registro condicionado, cuyos requisitos eran más accesibles que los exigidos para obtener el registro definitivo, pero implicaba que el partido en cuestión debía refrendar su registro en las elecciones, mediante la obtención de un porcentaje mínimo del 1.5\% de los votos válidos; además que se autorizó el acceso a financiamiento público y a espacios estatales en los medios de comunicación y se materializó la posibilidad de que los partidos políticos nacionales pudieran participar en las elecciones estatales y municipales. ${ }^{28}$

En 1986 se amplió de 100 a 200 el número de diputados elegidos mediante el principio de representación proporcional, mediante listas cerradas y bloqueadas, con lo que el tamaño de la Cámara aumentó para llegar a 500 integrantes; aunado a ello, se suprimió la cláusula que impedía al partido que hubiera obtenido más del $60 \%$ de los votos participar en el reparto de las diputaciones de representación proporcional, que había excluido al PRI de acceder a escaños asignados por ese principio; se estableció una cláusula de gobernabilidad para impedir la subrepresentación del partido mayoritario en esa cámara, garantizándole que, al menos, contaría con un porcentaje de diputados igual al de su votación.

Uno de los cambios más relevantes de esta reforma fue la modificación de la integración de la Comisión Federal Electoral, pues la participación de los partidos políticos en su interior, pasó de ser igualitaria a proporcional, lo que evidentemente dio al PRI total control de aquella. ${ }^{29}$

En este escenario, la participación de los partidos políticos de oposición fue cada vez mayor, lo que dificultó la contienda electoral

28 Véase Córdova Vianello, Lorenzo, "La reforma electoral y el cambio político en México", en Zovatto, Daniel y Orozco Henríquez, J. Jesús (coords.) Reforma política y electoral en América Latina 1978-2007, México, Universidad Nacional Autónoma de México, Idea Internacional, 2008, pp. 659 a 662.

29 Idem. 
para el PRI en 1988 (entre los candidatos Carlos Salinas de Gortari -PRI- y Cuauhtémoc Cárdenas Solórzano -PRD-) y en 1989 permitió el triunfo del candidato del PAN (Ernesto Ruffo Appel) en las elecciones para gobernador en Baja California, a partir de donde se inició una creciente ola de triunfos para la oposición en toda la República con la correspondiente pérdida de mayoría del PRI en los congresos locales. ${ }^{30}$

Por su parte, la reforma de 1989-1990 trajo cambios substanciales de entre los cuales el más relevante fue que el 11 de octubre de 1990 se suprimió la Comisión Federal Electoral y se creó el Instituto Federal Electoral como organismo público dotado de personalidad jurídica y patrimonio propio, aun cuando el Poder Ejecutivo mantenía el control del organismo a través de la Secretaria de Gobernación. ${ }^{31}$

Aunado a esto, se tomaron otras medidas como la construcción de un nuevo padrón electoral, un proceso de insaculación para la selección de los ciudadanos que integrarían las mesas directivas de casillas durante las elecciones y se sentaron las bases del esquema de financiamiento público de los partidos. ${ }^{32}$

En 1993 se estableció que ahora correspondería a los consejeros del IFE emitir la declaración de validez de las elecciones y en 1994 se efectuaron modificaciones a la legislación electoral secundaria aparentemente con la finalidad de lograr mejores condiciones para la oposición. Sin embargo, el electorado votó nuevamente por el candidato del Partido Revolucionario Institucional, Ernesto Zedillo Ponce de León. ${ }^{33}$

30 González Ulloa Aguirre, Pablo Armando, "Alternancia en las elecciones subnacionales en México ¿isíntoma de democratización?”, Estudio político, núm. 40, 2017, pp. 47-69. <http://www. scielo.org. mx/ pdf/ep/n40/0185-1616 -ep-40-0 0047.pdf $>$, consultado el 4 de mayo de 2018.

31 Véase Navarrete Vela, Juan Pablo, op. cit., p. 135.

32 Véase Córdoba Vianello, Lorenzo, op. cit. p. 663.

33 Véase Navarrete Vela, Juan Pablo, op. cit., p. 135. 
Esta reforma también dio ciertas facultades de fiscalización al IFE para revisar que la información financiera reportada por los partidos políticos correspondiera con su realidad. Aunado a ello, surgió la figura de los observadores electorales; pero una de las innovaciones más importantes fue que se atribuyó al Tribunal Federal Electoral, la función de calificar la elección de diputados y senadores. ${ }^{34}$

Finalmente, la reforma político-electoral de 1996 fue un arreglo negociado por los tres principales partidos (PAN; PRI y PRD) para garantizar mayores condiciones a la competencia política. En esta ocasión se estableció que el límite máximo de representación de la primera fuerza electoral en la conformación de la Cámara de Diputados fuera de 300 diputados electos por ambos principios, es decir, un 60 por ciento de los 500 escaños. También se fijó un mínimo de $2 \%$ de la votación para que un partido mantuviera y accediera a los 200 escaños de representación proporcional; además de que se incorporó este principio a la Cámara de Senadores, a fin de que se eligieran 32 por este mecanismo y se reconoció también la figura de Agrupaciones Político-Nacionales como instrumentos de desarrollo de la vida democrática. ${ }^{35}$

Pero sobre todo, uno de los efectos más importantes de esta reforma, fue que se dotó de autonomía constitucional al IFE, ${ }^{36}$ con lo que se suprimió la participación del gobierno en el manejo de las elecciones; además, se introdujo la posibilidad de presentar ante la Suprema Corte de Justicia de la Nación, acciones de inconstitucionalidad en contra de las leyes electorales.

Por otra parte, el régimen del Distrito Federal se modificó sustancialmente; ya que a partir de 1996 se estableció que los ciudadanos

\footnotetext{
34 Véase Córdoba Vianello, Lorenzo, op. cit. pp. 665-666.

35 Véase Navarrete Vela, Juan Pablo, op. cit., p. 136.

36 Este tema se desarrollará con mayor amplitud en párrafos subsiguientes.
} 
podrían elegir directamente a su jefe de Gobierno y la Asamblea de Representantes se transformó en Asamblea Legislativa. ${ }^{37}$

Estas nuevas reglas trajeron resultados favorables para la oposición. En las elecciones de 1997, el PRI perdió, por primera vez en su historia, la mayoría absoluta en la Cámara de Diputados, por lo que a partir de entonces la aprobación de leyes y la toma de decisiones presupuestales ha debido precederse de negociaciones y consensos entre las distintas fuerzas políticas, ya que unidos, los diputados de la oposición han representado la fuerza mayoritaria de la cámara. Además, esta apertura trajo como resultado que el primer cargo de jefe de gobierno lo ganara el candidato del Partido de la Revolución Democrática (PRD) Cuauhtémoc Cárdenas. ${ }^{38}$

En este escenario, las elecciones de 2000 fueron decisivas para materializar la alternancia. En esta ocasión los recursos con que contaban los candidatos eran similares y la plataforma jurídica y política en la que competían fue decisiva para que el candidato de la coalición formada por el Partido Acción Nacional (PAN) y el Partido Verde Ecologista de México (PVEM), Vicente Fox, obtuviera el triunfo y se erigiera como el primer Presidente de la alternancia.

De esa misma elección también resultó un Congreso en el que ningún partido contaba con mayoría absoluta en ninguna de las dos cámaras; lo cual se repitió en la intermedia de 2003 (que renovó la Cámara de diputados) y en al presidencial de 2006; en las que ningún órgano político obtuvo la fuerza necesaria para alcanzar por sí solo la mayoría en los órganos de representación. ${ }^{39}$

Aquí se da un punto de inflexión en el que la fuerza de la figura presidencial empieza a menguar, ante el fortalecimiento de los titulares de los otros dos poderes (Legislativo y Judicial).

\footnotetext{
37 Véase Navarrete Vela, Juan Pablo, op. cit., pp. 136-137.

38 Véase Córdoba Vianello, Lorenzo, op. cit. pp. 672-674.

39 Idem.
} 
Esto, como resultado del largo proceso que se expuso brevemente en este apartado, y que correspondió a un periodo muy importante en la historia constitucional y política de México; sobre todo, en lo que se refiere a la forma de entender la distribución de funciones estatales y a la superposición sobre los otros poderes de que hasta entonces había gozado el titular del Ejecutivo.

A juicio de Pedro Salazar Ugarte, el papel del Poder Ejecutivo en el régimen constitucional mexicano se ha transformado profundamente por dos vías, en primer término la relativa a los cambios políticos e institucionales que poco a poco fueron desarticulando las llamadas facultades meta constitucionales del Presidente, y que, en adición a lo expresado por el autor, también trajeron el fin del régimen de partido hegemónico.

En segundo lugar, la creación de los órganos constitucionales autónomos fue sustrayendo al Ejecutivo de áreas y funciones estratégicas, por lo que cada uno de estos órganos representa una alteración en las atribuciones constitucionales que originalmente se habían asignado al Presidente de la República y a la administración a su cargo. ${ }^{40}$

La pregunta que surge aquí es, ¿quien ostenta el poder político que inicialmente correspondía al ejecutivo y que hoy recae en los órganos constitucionales autónomos?

La respuesta que se plantea en este trabajo, es que esa fuerza política de la que se ha despojado a la figura presidencial, recae ahora en los partidos.

Ya diversos autores han advertido la fuerte participación que los partidos tienen en la división del poder político. Esta incidencia es más fuerte en unos sistemas que en otros (suele ser más evidente en regímenes parlamentarios); no obstante, es obvio que estos órganos

40 Cfr. Salazar Ugarte, Pedro, El Poder Ejecutivo en la Constitución mexicana. Del metaconstitucionalismo a la constelación de autonomías, México, Fondo de cultura Económica, 2017, pp. 105-106. 
son un factor muy importante a tomar en cuenta en lo relativo al ejercicio del poder público. ${ }^{41}$

\section{SURGIMIENTO DE LOS ÓRgANOS CONSTITUCIONALES Autónomos EN MÉxico}

La historia de los órganos constitucionalmente autónomos en México comenzó a escribirse en 1993, durante el sexenio de Carlos Salinas de Gortari, cuando se otorgó autonomía constitucional al Banco Central de México. ${ }^{42}$

Aunque en la adición constitucional de referencia no se precisó cuál sería el órgano de gobierno del Banco Central, ni se señaló el proceso de su designación; a juicio de Loreto Verdejo Villasis, de la exposición de motivos en la iniciativa de reforma enviada por el ejecutivo federal al legislativo, se aprecia que la autonomía otorgada al Banco de México tiene por objeto que los poderes tradicionales no ejerzan presión sobre este, a efecto de satisfacer intereses personales. ${ }^{43}$

Poco después, en 1996, durante el régimen presidencial de Ernesto Zedillo, se otorgó autonomía constitucional al entonces Instituto

41 Véase Carbonell, Miguel y Salazar, Pedro, División de poderes y régimen presidencial en México, México, UNAM, 2006, pp. 55 a 59.

42 Mediante decreto publicado en el diario Oficial del Federación el 20 de agosto de 1993, se adicionó el párrafo sexto cuyo contenido es el siguiente: "El Estado tendrá un banco central que será autónomo en el ejercicio de sus funciones y en su administración. Su objetivo prioritario será procurar la estabilidad del poder adquisitivo de la moneda nacional, fortaleciendo con ello la rectoría del desarrollo nacional que corresponde al Estado. Ninguna autoridad podrá ordenar al banco conceder financiamiento".

43 Cfr. Verdejo Villasis, Loreto, "Los organismos constitucionales autónomos en la clásica división de poderes; crisis o evolución", Revista electrónica de posgrado en Derecho, Universidad Iberoamericana Puebla, México, 2010, p. $10<\mathrm{https}$ // nanopdf.com/download/8107kb-universidad-iberoamericana-puebla_pdf $>$, consultado el 21 de mayo de 2018. 
Federal Electoral (hoy Instituto Nacional Electoral); ${ }^{44}$ cuyo objeto principal es preservar los principios de certeza, objetividad, legalidad, imparcialidad y profesionalismo que rigen la función electoral.

Al incluirlo en la Constitución, se le dotó de paridad de rango con otros órganos del Estado y de un ámbito material de competencia constitucionalmente determinada. ${ }^{45}$

El texto constitucional precisó que el Consejo General sería su órgano superior de dirección y se integraría por un Consejero Presidente y ocho consejeros electorales (con voz y voto), y que además, concurrirían con voz pero sin voto, los consejeros del Poder Legislativo, los representantes de los partidos políticos y un Secretario Ejecutivo.

Añadió, que el consejero Presidente y los consejeros electorales del Consejo General serían elegidos, sucesivamente, por el voto de las dos terceras partes de los miembros presentes de la Cámara de Diputados, o en sus recesos por la Comisión Permanente, a propuesta de los grupos parlamentarios. Conforme al mismo procedimiento, se designarían ocho consejeros electorales suplentes.

Posteriormente, en 1999 (también durante el sexenio de Zedillo), se reformó el apartado B del artículo 102 constitucional, para dotar de autonomía a la Comisión Nacional de Derechos Humanos.

En el decreto de reforma, se estableció que el citado organismo contaría con autonomía de gestión y presupuestaria, personalidad jurídica y patrimonio propios; y que además tendría un Consejo Consultivo integrado por diez consejeros elegidos por el voto de las dos terceras partes de los miembros presentes de la Cámara de

44 Decreto de reformas publicado el 22 de agosto de 1996 que reestructuró el artículo 41 de la Constitución Mexicana.

45 Cfr. Pedroza de la Llave, Susana Thalía, 'Los órganos constitucionales autónomos en México", en Serna De la Garza, José María y Caballero Juárez, José Antonio (eds.) México, Instituto de Investigaciones Jurídicas, Universidad Nacional Autónoma de México, 2002, p. 186. <https://archivos.juridicas.unam.mx/ www/bjv/libros/1/306/7.pdf>, consultado el 19 de mayo de 2018. 
Senadores o, en sus recesos, por la Comisión Permanente del Congreso de la Unión, con la misma votación calificada. Añadió que el Presidente de la Comisión Nacional de los Derechos Humanos y del Consejo Consultivo, sería elegido en la misma forma, que duraría en su encargo cinco años, podría ser reelecto por una sola vez y sólo podría ser removido de sus funciones por causas graves previstas en la propia constitución. ${ }^{46}$

Más adelante, en diciembre de 2003, durante la segunda mitad del sexenio de Vicente Fox Quezada, el Senado aprobó el proyecto de decreto que dotó de autonomía constitucional al Instituto Nacional de Estadística, Geografía e Informática. ${ }^{47}$

En esa reforma constitucional se dividió en dos secciones al artículo 26 constitucional, en cuyo apartado A se dejaron las disposiciones relativas a la planeación democrática del desarrollo, mientras que en el B se estableció la autonomía constitucional de un órgano encargado del Sistema Nacional de Información Estadística y Geográfica, cuyos datos serían oficiales y de uso obligatorio para la Federación, Estados, Distrito Federal y Municipios, en términos de lo que estableciera la ley.

Se dotó de autonomía técnica y de gestión, personalidad jurídica y patrimonio propios al INEGI, y se determinó que lo encabezaría una Junta de Gobierno integrada por cinco miembros, uno de los cuales sería su Presidente, todos designados por el Presidente de la República con aprobación de la Cámara de Senadores o la Comisión Permanente (en los recesos de aquella). ${ }^{48}$ de 1999.

47 Zamora Flores, José Luis, "El INEGI: Nuevo Órgano Constitucional Autónomo", Revista del Posgrado en Derecho de la UNAM, Vol.2, núm.3, 2006. pp. 206-207.

48 Apartado B del artículo 26 constitucional, según el Decreto por el que se reforman los artículos 26 y 73 fracción XXIX-D de la Constitución Política de los Estados Unidos Mexicanos, publicado en el Diario Oficial de la Federación de 7 de abril de 2006. 
A partir de entonces se han multiplicado en forma abrumadora los organismos directamente creados en la Constitución, con funciones específicas independientes de los poderes del Estado y que gozan de autonomía funcional y financiera respecto de aquellos.

En 2013 (en la primera mitad del sexenio de Enrique Peña Nieto), se reformó el artículo $3^{\circ}$ constitucional, dotando de autonomía al Instituto Nacional para la Evaluación de la Educación (INEE), que desde su creación en 2002 y hasta entonces, había sido un organismo descentralizado del Ejecutivo a través de la Secretaría de Educación Pública. ${ }^{49}$

En julio de ese mismo año, se reformó el artículo 28 constitucional y se creó el Instituto Federal de Telecomunicaciones (IFETEL), al cual se le dotó de personalidad jurídica y patrimonio propio, y se le atribuyeron facultades esenciales para el desarrollo de las actividades relacionadas con las telecomunicaciones. ${ }^{50}$

Con la reforma al artículo 28 constitucional a que se hace referencia en el párrafo anterior, la Comisión Federal de Competencia, que desde su creación en la Ley Federal de Competencia Económica de 1992, había sido un órgano desconcentrado de la Secretaría de Economía, se transformó en el órgano constitucional autónomo Comisión Federal de Competencia Económica (COFECE), con facultades de regulación en áreas estratégicas de la economía nacional. ${ }^{51}$

En 2014 se reformó el artículo 26 constitucional, cuyo efecto fue transformar al Consejo Nacional de Evaluación de la Política del Desarrollo Social (creado en 2001 en la Ley General de Desarrollo Social como un organismo descentralizado de la Secretaría de Desarrollo Social. La facultades de este órgano se relacionan con la medición de los programas, objetivos, metas y acciones de

\footnotetext{
49 Salazar Ugarte, Pedro, op. cit., pp. 125-128.

50 Ibidem, pp. 131-132.

51 Ibidem, pp. 134-135.
} 
la política de desarrollo social, respecto de los cuales podrá emitir recomendaciones. ${ }^{52}$

En febrero de 2014 se produjo la reforma al artículo $6^{\circ}$ constitucional con la que emergió el órgano constitucional autónomo Instituto Nacional de Transparencia, Acceso a la Información y Protección de Datos Personales (INAI); cuyo nacimiento había acontecido en junio de 2002, en la Ley Federal de Transparencia y Acceso a la Información Pública Gubernamental, bajo la denominación de Instituto Federal de Acceso a la Información Pública (IFAI), como parte del Poder Ejecutivo.

Seis meses después se modificó la ley para situar al instituto como un organismo descentralizado, no sectorizado, con personalidad jurídica y patrimonio propios; calidad que conservó hasta que obtuvo su autonomía constitucional. ${ }^{53}$

Finalmente, en la misma reforma de 2014 en la que se dotó de autonomía al CONEVAL, se reformó el artículo 102 constitucional en el sentido de desaparecer a la Procuraduría General de la República para dar paso a la Fiscalía General de la República como un órgano público autónomo. ${ }^{54}$

Como se aprecia de los datos expuestos en este apartado, en un solo se sexenio se duplicó la cantidad de autonomías constitucionales. ¿Acaso esa situación tendrá alguna relación con la extinción del régimen de partido hegemónico y con la incertidumbre en la fuerza política de la que emergerá el próximo Presidente de la República?

52 Ibidem, pp. 135-136.

53 Ibidem, pp. 140-142.

54 Ibidem, p. 146. 
IV. ANÁlisis DE LA RELACIÓN ENTRE LA ALTERNANCIA DE PARTIDO DEL QUE EMERGE EL PRESIDENTE DE LA REPÚBLICA Y EL INCREMENTO DE LOS ÓRGANOS CONSTITUCIONALES AUTÓNOMOS

Con base en lo anterior, se tiene que el objeto de estudio en este trabajo es la disgregación del poder público que ejercía el titular del Ejecutivo, su trasferencia a los órganos constitucionales autónomos y el posible vínculo de esta circunstancia con la extinción de la hegemonía de partido. Esto, con la finalidad de determinar una eventual relación entre estos fenómenos.

En cuanto a la primera incógnita que se planteó, se obtuvo que existe una relación muy fuerte entre la hegemonía de partido y el presidencialismo mexicano; debido a que se trata de dos estructuras que se nutren recíprocamente, en tanto que la existencia y fortalecimiento de una determina a la otra.

Para explicar lo anterior debemos decir que la hegemonía de partido constituyó uno de los factores que dotó de fuerza del presidencialismo puro de nuestro país; pues la supremacía de una solo órgano político traía como consecuencia que los integrantes de los poderes Legislativo y Judicial también emanaran de entre los militantes del partido y con ello, compartían los mismos intereses del titular del Ejecutivo. Por su parte, el presidencialismo apuntalaba la hegemonía, pues las elecciones las realizaban y calificaban órganos del Poder Ejecutivo, lo que abonaba a perpetuar a los candidatos del partido en el poder, en la mayoría de los cargos de elección popular.

De esta forma, aunque formalmente el Estado y el partido eran cosas distintas, en los hechos sus intereses solían confundirse.

No obstante, de manera por demás justificada, las fuerzas políticas del país distintas del PRI, reclamaban espacios en la administración pública, así como condiciones que les permitieran competir en igualdad de circunstancias por obtenerlos. Estos requerimientos 
dieron lugar a tímidas reformas en 1971 y 1973 que no resultaron suficientes para materializar las demandas.

En 1977 se produjo otra reforma electoral cuyo objeto era abrir esos espacios antes negados, a través del mecanismo de representación proporcional en la Cámara de Diputados y también se diseñó el llamado "registro condicionado", que permitió el incremento de partidos políticos.

En 1986 se amplió de 100 a 200 el número de diputados elegidos mediante el principio de representación proporcional y el tamaño de la Cámara aumentó para llegar a 500 integrantes; pero en contrapartida, se suprimió la cláusula que impedía al partido que hubiera obtenido más del 60\% de los votos participar en el reparto de las diputaciones de representación proporcional (lo que favoreció al PRI) y se estableció una cláusula de gobernabilidad que aseguraba que el partido mayoritario en esa cámara (PRI), contaría al menos con un porcentaje de diputados igual al de su votación.

Para terminar de afianzar este dominio, se determinó que la participación de los partidos políticos en la Comisión Federal Electoral sería proporcional, con lo que el PRI ganó el control total de aquella.

Aun así, para entonces ya había más partidos dotados de financiamiento público y espacios en los medios de comunicación; lo que redundó en una mayor participación de las fuerzas políticas opositoras.

De este modo, el triunfo de Carlos Salinas de Gortari -PRI- sobre Cuauhtémoc Cárdenas Solórzano-PRD- fue muy cuestionado, dado el escaso margen de ventaja en el número de votos válidos obtenidos por el primero y por la falta de transparencia por parte de la Comisión Federal Electoral durante el procesamiento de los resultados electorales. Esta mala racha del PRI aumentó rápidamente, pues en 1989 el candidato del PAN ganó la gubernatura en Baja California, triunfo al que le siguieron otros en todo el país. 
Por su parte, la reforma de 1989-1990, que entre otras cosas creó el Instituto Federal Electoral como organismo público dotado de personalidad jurídica y patrimonio propio, fortaleció a la oposición, aunque en la elección presidencial el PRI volvió a obtener el triunfo.

Finalmente, la reforma político-electoral de 1996 dio autonomía constitucional al IFE y estableció que los ciudadanos del Distrito Federal podrían elegir directamente a su jefe de Gobierno. A partir de esto, en la elección de 1997 el PRI perdió la mayoría absoluta en la Cámara de Diputados, y el primer cargo de jefe de gobierno lo ganó el candidato del PRD; y para el año 2000 se concretó la extinción de la hegemonía a través del triunfo del PAN en la elección presidencial.

Como se aprecia, el contexto en el que se dio la alternancia en el cargo de Presidente de la República representó un proceso largo y paulatino. Así se resuelve la segunda incógnita planteada al inicio del presente trabajo.

En relación con la tercera interrogante, Sergio Márquez Rábago comenta que los órganos constitucionalmente autónomos surgieron cuando el sistema político de partido hegemónico mostró signos de extinción. Carlos Salinas de Gortari promovió el primero en 1993 (Banco Central de México), logrando con ello el manejo financiero transexenal de modo que aunque el PRI no ganara las elecciones presidenciales, manejaría las finanzas públicas unos años más a través de un Banco de México autónomo. ${ }^{55}$

Esta afirmación no parece descabellada si se toman en cuenta los acontecimientos que precedieron a la derrota del PRI en las elecciones presidenciales de 2000; concretamente, el difícil triunfo del propio Salinas en la elección de 1988.

Efectivamente, de la serie de acontecimientos y reformas desglosadas en este trabajo, se puede concluir que existe una relación in-

55 Cfr. Márquez Rábago, Sergio R., Derecho Constitucional en México, Porrúa Print, México, 2016, pp. 79-81. 
versamente proporcional entre la hegemonía de un partido político y la inclusión de facultades autónomas en la Constitución; ya que mientras mayor fue la fuerza del régimen de hegemonía de partido, menor fue la tendencia a disgregar el ejercicio del poder en órganos ajenos a los poderes tradicionales.

Se sostiene este aserto, pues durante los años de 1929 a 1988 en que la supremacía del PRI era incuestionable y resultaba altamente improbable que perdiera la titularidad del Ejecutivo, no se registró intento alguno por crear órganos con facultades constitucionales coyunturales para la buena marcha del Estado y que además no dependieran de alguno de los tres poderes tradicionales. Al contrario, el presidencialismo puro era perfectamente tolerado y la preeminencia del titular del Ejecutivo era generalmente aceptada.

En cambio, en cuanto el sistema empezó a dar señales de que esta permanencia peligraba, se produjo la reforma constitucional con la que se inició la lista de los, hasta hoy, diez órganos autónomos cuyo rango constitucional los coloca al mismo nivel con los poderes en los que, de acuerdo con el artículo 49 constitucional se divide el poder para su ejercicio.

Durante el sexenio de Zedillo (último Presidente prísta previo a la alternancia), se crearon dos órganos constitucionalmente autónomos y solo uno durante el periodo presidencial de Fox (primer Presidente de la alternancia); pero llama poderosamente la atención que a partir de que el PRI recuperó la titularidad del Ejecutivo (en 2012), se han multiplicado abrumadoramente las autonomías constitucionales; pues tan solo de 2013 a 2014 han surgido seis órganos de esta naturaleza.

No debe soslayarse que este impresionante número de depositarios de facultades constitucionales vitales para el funcionamiento del Estado, fue consecuencia del acuerdo alcanzado entre las distintas fuerzas políticas del país conocido como "pacto por México", que dio lugar a diversa reformas constitucionales conocidas como 
"estructurales", en áreas esenciales como educación, telecomunicaciones, acceso a la información, energía, entre otras.

Con esto, el concepto de división de poderes en el constitucionalismo mexicano se ha venido matizando, ya que la gran cantidad de facultades que anteriormente se concentraban a nivel constitucional en el Ejecutivo, hoy se encentra distribuidas en diez órganos que no dependen de aquel ni de ningún otro poder, porque son autónomas.

En esta nueva dinámica de entender el ejercicio del poder público destaca el papel que los partidos políticos juegan en el sistema actual; pues habiendo pluralidad de fuerzas en las cámaras y existiendo incertidumbre sobre el partido del que emergerá el Ejecutivo, el hecho de que la designación de los titulares de los órganos constitucionalmente autónomos se encuentre a cargo de estos dos poderes (Ejecutivo y Legislativo), evidencia el grado de influencia de esos institutos políticos.

\section{v. Conclusiones}

Con base en las respuestas a estas premisas, se concluye que se comprobó la hipótesis planteada en este trabajo, pues efectivamente, los órganos constitucionales autónomos son una forma de disgregación del poder político cuyo surgimiento e incremento se relaciona con la terminación de la hegemonía partidista.

\section{Vi. Fuentes}

\section{BibliográficAS}

Arroyo Ramírez, Miguel, "Notas al Presidencialismo Mexicano", en Carbonell, Miguel, Fix-Fierro, Héctor, González Pérez, Luis Raúl y Valadés, Diego (coords.), Estado Constitucional, derechos humanos, justicia y vida universitaria. Estudios en homenaje a forge Carpizo, México, Universidad Nacional Autónoma de México Instituto de Investigaciones Jurídicas, 2015. 
Cabrera Acevedo, Lucio, El Constituyente de 1917 y el Poder Fudicial de la Federación, una visión del siglo $X X$, México, Suprema Corte de Justicia de la Nación, 2002.

Carbonell, Miguel y Salazar, Pedro, División de poderes y régimen presidencial en México, México, UNAM, 2006.

Carpizo, Jorge, "Presidencialismo Puro", en Flores Mendoza, Imer Benjamín (ed. y coord.), Doctrina Constitucional Mexicana colección INEHRM, México, Senado de la República LXIII Legislatura, Secretaría de Cultura, Instituto Nacional de Estudios Históricos de las Revoluciones de México, Instituto de Investigaciones Jurídicas-UNAM, 2017.

Córdova Vianello, Lorenzo, "La reforma electoral y el cambio político en México", en Zovatto, Daniel y Orozco Henríquez, J. Jesús (coords) Reforma política y electoral en América Latina 1978-2007, México, Universidad Nacional Autónoma de México, Idea Internacional, 2008.

MÁrQuez, Daniel, "Fenomenología, presidencialismo mexicano y facultades meta constitucionales", en Carbonell, Miguel, Fix-Fierro, Héctor, González Pérez, Luis Raúl y Valadés, Diego (coords), Estado Constitucional, derechos humanos, justicia y vida universitaria. Estudios en homenaje a Forge Carpizo, México, Universidad Nacional Autónoma de México Instituto de Investigaciones Jurídicas, 2015.

Márquez Rábago, Sergio R., Derecho Constitucional en México, Porrúa Print, México.

Pedroza de la Llave, Susana Thalía, "Los órganos constitucionales autónomos en México", en Serna De la Garza, José María y Caballero Juárez, José Antonio (eds.) México, Instituto de Investigaciones Jurídicas, Universidad Nacional Autónoma de México, 2002.

Salazar Ugarte, Pedro, El Poder Ejecutivo en la Constitución mexicana. Del metaconstitucionalismo a la constelación de autonomías, México, Fondo de Cultura Económica, 2017.

Sartori, Giovanni, Partidos y sistemas de Partidos, $2^{\mathrm{a}}$ Ed., trad. de Fernando Santos Fontela, Madrid, Alianza Editorial, 2005. 
Aguilar Gamín, Héctor, "Nocturno de la democracia mexicana", Nexos, 1 de mayo de 2016.

Bertaccini, Tiziana, "Volver a las orígenes del Partido Revolucionario Institucional: una mirada comparativa con el Partido Nacional Fascista", Revista Electrónica Iberoamericana, Centro de Estudios Iberoamericanos, vol. 10, num. 2, 2016.

Del Castillo Troncoso, Alberto, "El movimiento estudiantil de 1968 narrado en imágenes" Revista Scielo, año 23, núm. 68, septiembre-diciembre de 2008.

Fernández, Nuria, "La reforma política: Orígenes y limitaciones", Cuadernos Políticos, núm. 16, México, editorial Era, abril-junio de 1978.

González Ulloa Aguirre, Pablo Armando, "Alternancia en las elecciones subnacionales en México ¿síntoma de democratización?”, Estudio político, núm. 40, 2017.

Navarrete Vela, Juan Pablo, "Sistema político mexicano: Desarrollo y reacomodo del poder". Ibero Fórum, Universidad Iberoamericana, vol III, núm. 6, julio-diciembre, 2008.

Rodríguez Montaño, Luis Carlos y Pineda Pablos, Nicolás, "La declinación de la hegemonía del PRI en los gobiernos estatales de México, 1989-2014”. Revista Scielo, vol. 29, núm. 69, 2017.

Verdejo Villasis, Loreto, "Los organismos constitucionales autónomos en la clásica división de poderes; crisis o evolución", Revista electrónica de posgrado en Derecho, Universidad Iberoamericana Puebla, México, 2010.

Zamora Flores, José Luis, "El INEGI: Nuevo Órgano Constitucional Autónomo", Revista del Posgrado en Derecho de la UNAM, Vol.2, núm.3, 2006.

Zúñiga Aguilar, Manuel, "Partido Nacional Revolucionario (PNR). Método y práctica en la selección de candidatos a puestos de elección popular (1929-1938)", Estudios Políticos, México, novena época, núm. 24, septiembre-diciembre, 2011. 
_- "89 datos del PRI en 89 años de historia", Expansión en alianza con CNN, México, 4 de marzo de 2018.

LEgisLativas

Constitución Política de los Estados Unidos Mexicanos.

\section{Electrónicas}

Dicgionario de la Real Academia Española, Versión virtual, < http:// dle.rae.es $/$ ? id $=\mathrm{K} 5 \mathrm{aAU}$ ck $>$.

Instituto Nacional Electoral, Directorio y documentos básicos, <http://portalanterior.ine.mx/archivos3/portal/histórico/ contenidoDirectorio_y_documentos_basicos/>.

Pérez Guilhou, Dardo, "Presidencialismo, caudillismo y populismo", Comunicación en sesión privada de la Academia Nacional de Ciencias Morales y Políticas, el 13 de abril de 2005, <https://www. yumpu. com/es/document/ view/29447475/presidencialismo caudillismo-y-populismo-academia-nacional-de- $>$.

— - Presidencialismo y Parlamentarismo en la jurisprudencia constitucional. IX Conferencia Iberoamericana de Justicia Constitucional. IX Conferencia Iberoamericana de Justicia Constitucional. Cádiz, 17, 18 y 19 de mayo de 2012, <https://www. Tribunal constitucional. es/ es/ publicaciones/ Publicaciones /CIJC -IX.pdf>. 